\title{
Virtual Building Medol to Predict Hourly Cooling Load for District Buildings in Urban Planning
}

\author{
Xiang YUAN* \\ School of Civil Engineering, \\ North China University of Technology \\ Beijing, China \\ e-mail: yx_ncut@163.com,www.ncut.edu.cn
}

\author{
Wei-ding LONG \\ Sino-German School of Applied Sciences, \\ Tongji University \\ Shanghai, China \\ e-mail: weidinglong163@163.com
}

\begin{abstract}
Load prediction is the basis work of district energy planning. Establishing simulation models is a valid method for hourly cooling load. Considering regulatory indexes of buildings play a bridge role between single buildings and the district in urban regulatory planning, the paper discusses relationships of hourly cooling loads between single buildings and the district. The paper builds a virtual building model whose distribution of hourly cooling loads per unit volume is the same as that of superposition of all single buildings in the district. Parameter values of simulation model for the virtual building can been determined by buildings in the district with specific regulations. In the stage of urban regulatory planning, virtual building parameter values can deduced from regulatory indexes. At last, the process of establishing the method with regulatory indexes is proposed in the paper.
\end{abstract}

Keywords-Cooling load; Prediction; Energy planning; Regulatory index; Building; district.

\section{INTRODUCTION}

The rate of urbanization has reached $53.7 \%$ in 2013 with the rapid urbanization process in China. Meanwhile, building energy consumption increased in construction of urbanization, which is important to pay attention to energy consumption in urban comprehensive planning or regulatory planning. So building energy planning is essential in the space scale of district about several square kilometers in area. Detailed district building energy planning, which is a transitional step between urban energy strategy planning and building designing, can provide the basis for district energy utilization and management [1].

Load prediction is the basis work of district energy planning. Two kinds of methods are often used. The first is historical data extrapolation, such as parametric regression $[2,3]$, neural networks [4,5] and linear relationship statistics [6]. Existing design indicators are commonly obtained from historical data, which is used in load calculation for building cooling system design. This method is based on a large number of historical data, which will bring difficulties to preliminary stage of planning for district buildings because of lack of data. In addition, hourly cooling loads can't be obtained by this method.

The second method is to establish integrated simulation models combined with energy simulation software and other tools by considering the influence of building envelope thermal factors and internal factors [7]. Although district cooling loads can be acquired with building models, a mountain of work will be done with detailed information of each building including shape, size, function, envelope thermal factors, and so on. On the preliminary stage of planning, these conditions can't be fully afforded because construction solutions of single buildings in the district have not been proposed [8,9]. So how to determine building parameter values of simulation models is the critical problem. The more adjacent to actual values parameters are, the more accurate simulation values are. Now the typical method to establish simulation models is to select the representative building as the building model $[10,11]$.

In urban regulatory planning, regulatory indexes of buildings have been worked out and they reflect overall characteristic of district buildings. These indexes are relevant to single building factors such as the shape, volumes, functions, and so on. But in the two methods above, regulatory indexes were less concerned. If parameter values can been deduced from regulatory indexes, relatively accurate simulation models would be acquired. In other words, regulatory indexes can be considered as the bridge between single buildings and the district. So the first job is to find relationships of hourly cooling loads between single buildings and the district. The paper will build a virtual building model representing features of cooling loads for district buildings, and then get hourly cooling load of the whole district by simulating virtual building with simulation software.

\section{MODELING METHODOLOGY}

\section{A. Relationships of Cooling Load between District and Single Buildings}

As shown in figure1, Regarded as a physical system, a single building's external and internal disturbance variables can be seen as the input of the system, and cooling load as the output. The factors that produce external disturbance include outdoor climate and solar radiation. And internal disturbance factors include persons, indoor equipments, indoor lighting, and so on. In the same district, external disturbance is basically identical for different buildings neglecting the influence of winds for building surface heat convection, though buildings of different functions within different disturbance, which means all buildings of the same district are in the environment with the same outdoor temperature, humidity and solar radiation intensity. So a district thermal system model can established with input of 
unified external disturbance factors and integrated interference factors, the total load of district building as the output.

\section{External disturbance}

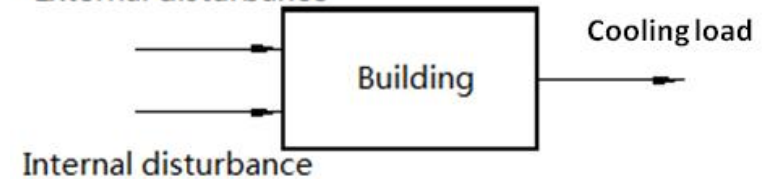

Figure 1. Schematic diagram of single building thermal system

As shown in figure 2 within the dotted line represents, an integrated building thermal system can be got for the district buildings. The system is similar to a single building. So the next work is to establish a single building model whose hourly load distribution is the same as that of superposition of all single buildings in the district.

Assumed there are $\mathrm{m}$ buildings in a district, and total instantaneous cooling load is $C L(\tau) . C L_{i}(\tau)$ is instantaneous cooling load of building $\mathrm{i}$ in the district. $C L_{i}(\tau)$ is the sum of $C L_{\text {out }, i}$ and $C L_{i n, i}$ :

$$
C L_{i}(\tau)=C L_{\text {out }, i}+C L_{\text {in }, i}
$$

where $C L_{\text {out }, i}$ is external disturbance instantaneous cooling load and $C L_{i n, i}$ is internal disturbance instantaneous cooling load. Then $C L(\tau)$ can be described:

$$
C L(\tau)=\sum_{i}^{m} C L_{i}(\tau)
$$

With Eq. (2) $C L(\tau)$ can be written as:

$$
C L(\tau)=\sum_{i}^{m} C L_{\text {out }, i}+\sum_{i}^{m} C L_{i n, i}
$$

The peak of instantaneous cooling load is regarded as the cooling load of the district:

$$
C L=\max [C L(\tau)]
$$

Building cooling load is the results of mutual influence of external factors and internal factors. It is necessary to build their respective models separately.

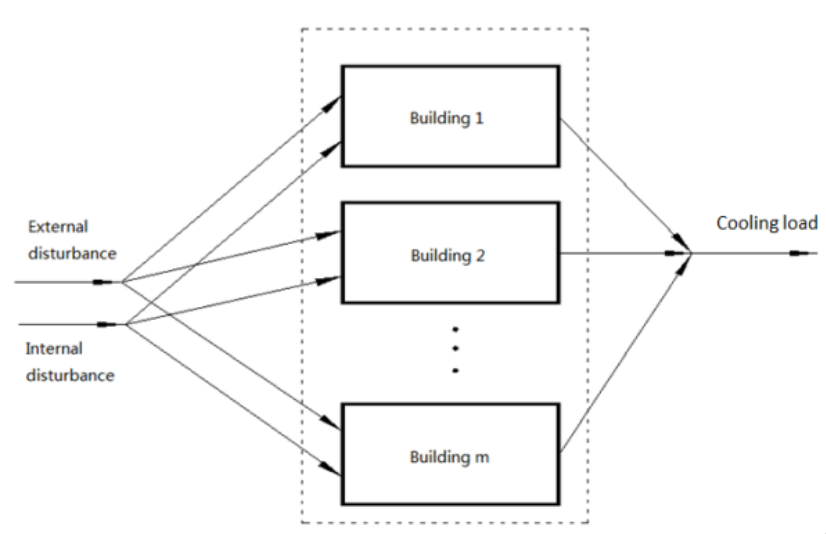

Figure 2. Schematic diagram of district building thermal system

\section{B. Integration Model of District buildings}

1) Conditions and The Goal of The Model

First, four conditions should be assumed:

a) There are almost rectangular buildings in the district, and the benchmark shape of buildings can be shaped as rectangle, which is reasonable on preliminary stage of planning. In fact, buildings with other shapes can be transformed into rectangular buildings. This part will not discuss in the paper, which would not influent logic of the methodology.

b) All buildings have the same orientation, implying each building elevation is parallel to any other elevations with corresponding orientation. The building with different orientation can also been transformed into the same orientation with specific rules [12].

c) Indoor environments of each building in the district are homogeneous with uniform air temperature and (2) humidity. In fact, different indoor environment can be corrected by coefficient of temperature and humidity, which will be discussed below.

d) The influence on cooling loads caused by shading between buildings is not considered.

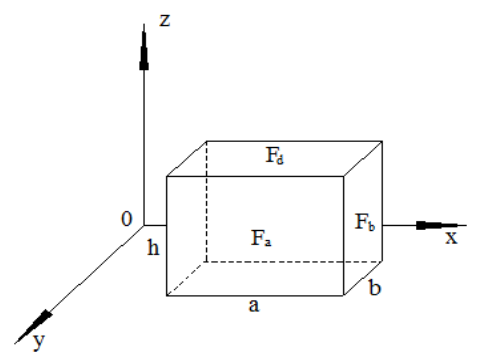

Figure 3. District building shape parameter

Assuming that there are $\mathrm{m}$ rectangle buildings named $\mathrm{B}_{1}$, $\mathrm{B}_{2}, \ldots, \mathrm{B}_{\mathrm{m}}$ with the same orientation, as shown in figure 3, the length of building sides in $\mathrm{x}$ direction are $\mathrm{a}_{1}, \mathrm{a}_{2}, \ldots, \mathrm{a}_{\mathrm{m}}$ and in $y$ direction are $b_{1}, b_{2}, \ldots, b_{m}$ respectively. The volume of a single building is $V_{i}=a_{i} \times b_{i} \times h_{i}$ and the district 
total volume is $V$. The single building surface area is $F$ including the roof area $F_{d}$, facade wall area in x direction $F_{a}$ with windows area $F_{a w}$, and facade wall area in y direction $F_{b}$ with windows area $F_{b w}$. In order to analyze the model conveniently, we assumes that all symmetry plane has the same area. Even symmetry planes have not equal areas, this method is also valid.

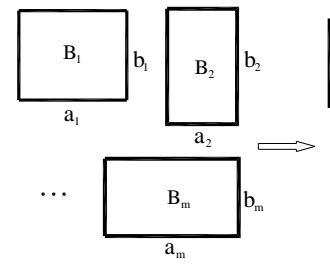

(a)

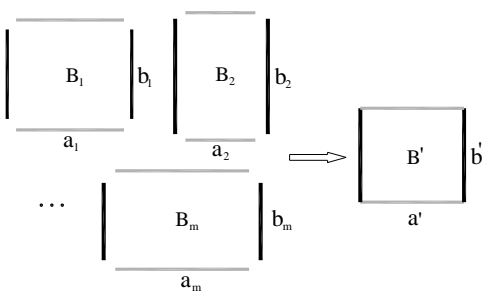

(b)

(c)
Figure 4. Integration model of district building

The goal is to find a virtual building, of which the instantaneous cooling load has the same distribution characteristics with the whole district. The procedure of integration model establishment can be showed as figure 4 . Facade walls with the same orientation and also internal factors will be integrated in particular methods. Then the goal building can be acquired. A detailed description of the methods follows.

2) Virtual building model only with external factors

It is necessary to establish the model with external and internal factors separately, in order to express the model logicality clearly.

Let denote $C L_{V i}$ is the instantaneous cooling load of a single building, and the instantaneous cooling load per unit volume of district building $C L_{V}(\tau)$ is:

$$
C L_{V}(\tau)=\frac{C L(\tau)}{V}
$$

The instantaneous cooling load of district building is:

$$
C L(\tau)=\sum_{i=1}^{m} V_{i} C L_{V i}
$$

For a single building $\mathrm{Bi}$, instantaneous cooling load per unit volume is:

$$
C L_{V i}=\frac{\left(F_{a i}-F_{a w i}\right) q_{a i}+\left(F_{b i}-F_{b w i}\right) q_{b i}+F_{d i} q_{d i}+\left(F_{a w i} q_{a w i}+F_{b w i} q_{b w i}\right)}{V_{i}}
$$

Where $q_{a} q_{b}, q_{d}$, are instantaneous cooling load per unit area of facade wall a, b and roof respectively; $q_{a w}, q_{b w}$ are instantaneous cooling load per unit area of facade window $a$, $b$ respectively; $F_{a}, F_{b}\left(F_{a w}, F_{b w}\right)$ are areas of facade wall (window) $a, b$.

After a long run, ground temperature difference heat transfer can be neglected, because of very small difference between ground temperature and indoor air temperature.

Eq. (6) can be transformed as:

$$
C L_{V i}=q_{a i} \frac{F_{a i}}{V_{i}}+q_{b i} \frac{F_{b i}}{V_{i}}+q_{d i} \frac{F_{d i}}{V_{i}}+\left(q_{a w i}-q_{a i}\right) \frac{F_{a w i}}{V_{i}}+\left(q_{b w i}-q_{a i}\right) \frac{F_{b w i}}{V_{i}}
$$

Let denote $m_{i}=V_{i} / V$ is the volume weighting of some one building to the district. By Eq. (4), (5), (7), we can obtain instantaneous cooling load per unit volume of district:

$$
C L_{V}(\tau)=\sum_{i} q_{a i} m_{i} \frac{2}{b_{i}}+\sum_{i} q_{b i} m_{i} \frac{2}{a_{i}}+\sum_{i} q_{d i} m_{i} \frac{1}{h_{i}}+\frac{1}{V} \sum_{i}\left(q_{a w i}-q_{a i}\right) F_{a w i}+\frac{1}{V} \sum_{i}\left(q_{b w i}-q_{b i}\right) F_{b w i}
$$

If all buildings in the district have uniform envelope materials, Eq.(8) can be written as:

$$
C L_{V}(\tau)=q_{a} \sum_{i} m_{i} \frac{2}{b_{i}}+q_{b} \sum_{i} m_{i} \frac{2}{a_{i}}+q_{d} \sum_{i} m_{i} \frac{1}{h_{i}}+\frac{\left(q_{a w}-q_{a}\right)}{V} \sum_{i} F_{a w i}+\frac{\left(q_{b w}-q_{b}\right)}{V} \sum_{i} F_{b w i}
$$

Then the following job is to establish a virtual building and determine its shape and thermodynamics parameter values according to district buildings. Assuming that there is a virtual cube building $B^{\prime}$ as shown in figure 4(c), the length, depth, height and the volume are $a^{\prime}, b^{\prime}, h^{\prime}, V^{\prime}$ respectively. By Eq.(6), the instantaneous cooling load per unit volume of building $B$ is:

$$
C L_{V}^{\prime}(\tau)=q_{a} \frac{2}{b^{\prime}}+q_{b} \frac{2}{a^{\prime}}+q_{d} \frac{1}{h^{\prime}}+\left(q_{a w}-q_{a}\right) \frac{F_{a w}^{\prime}}{V^{\prime}}+\left(q_{b w}-q_{b}\right) \frac{F_{b w}^{\prime}}{V^{\prime}}
$$

\section{a) The Shape Parameter of Building $B^{\prime}$}

In order to determine the shape parameter of building $B^{\prime}$, we consider first the simplest case, which all buildings of the district have uniform envelope materials. By comparison with Eq.(9) and Eq.(10), the first items are relative to the values of length, depth, and height, and the last items are relative to the area ratio of window to wall.

Let denote $C L_{V}^{\prime}(\tau)=C L_{V}(\tau)$, which means that building $\mathrm{B}^{\prime}$ and the district have the same instantaneous cooling load per unit volume distribution. With corresponding items equivalents between Eq.(9) and Eq.(10), the shape parameter of building B' can be determined, showed as Table 1. 
TABLE I. THE SHAPE PARAMETER AND AREA OF WINDOWS

\begin{tabular}{ccc}
\hline Building name & District buildings & Building $B^{\prime}$ \\
\hline Length of facade wall $a$ & $a_{1}, a_{2}, \cdots, a_{m}$ & $a^{\prime}=\frac{1}{\sum_{i} m_{i} \frac{1}{a_{i}}}$ \\
Length of facade wall $b$ & $b_{1}, b_{2}, \cdots, b_{m}=\frac{1}{\sum_{i} m_{i} \frac{1}{b_{i}}}$ \\
Building height & $h_{1}, h_{2}, \cdots, h_{m}$ & $h^{\prime}=\frac{1}{\sum_{i} m_{i} \frac{1}{h_{i}}}$ \\
Window area of facade wall $a$ & $F_{a w 1}, F_{a w 2}, \cdots, F_{a w m}$ & $F_{a w}^{\prime}=\frac{V^{\prime}}{V} \sum_{i} F_{a w i}$ \\
Window area of facade wall $b$ & $F_{b w 1}, F_{b w 2}, \cdots, F_{b w m}$ & $F_{b w}^{\prime}=\frac{V^{\prime}}{V} \sum_{i} F_{b w i}$ \\
\hline
\end{tabular}

Table 1 shows that the length, depth, and height of building $B^{\prime}$ are weighted harmonic means of district buildings respectively. The weight factor is the ratio of a single building volume to the sum of district buildings. The window area ratio is volume ratio of building $B^{\prime}$ to the sum. $B^{\prime}$

b) Outer Wall and Roof Thermal Factors of Building

The following job is to determine the outer envelope thermal factors in the condition of different materials. Although determined in the condition of uniform envelope materials, shape parameters in Table 1 are still valid, because they are underlying model.

In order to express relationships conveniently between following equations and above, several vectors are denoted:

$Q_{a}=\left[\begin{array}{ccc}q_{a 1} & & \\ & \ddots & \\ & & q_{a m}\end{array}\right]^{\prime} Q_{b}=\left[\begin{array}{lll}q_{b 1} & & \\ & \ddots & \\ & & q_{b m}\end{array}\right]{ }^{\prime} Q_{d}=\left[\begin{array}{lll}q_{d 1} & & \\ & \ddots & \\ & & q_{d m}\end{array}\right]$,

$A=\left[\begin{array}{lll}\frac{1}{a_{1}} & \cdots & \frac{1}{a_{m}}\end{array}\right]^{\prime} B=\left[\begin{array}{lll}\frac{1}{b_{1}} & \cdots & \frac{1}{b_{m}}\end{array}\right]^{\prime} H=\left[\begin{array}{lll}\frac{1}{h_{1}} & \cdots & \frac{1}{h_{m}}\end{array}\right], M=\left[\begin{array}{lll}m_{1} & \cdots & m_{m}\end{array}\right]^{T}$,

$K_{a}=\left[\begin{array}{ccc}K_{a 1} & & \\ & \ddots & \\ & & K_{a m}\end{array}\right] K_{b}=\left[\begin{array}{lll}K_{b 1} & & \\ & \ddots & \\ & & K_{b m}\end{array}\right], K_{d}=\left[\begin{array}{lll}K_{d 1} & & \\ & \ddots & \\ & & K_{d m}\end{array}\right]$,

where $Q_{a}, Q_{b}, Q_{d}$ are referred as instantaneous heat transfer vector for facade wall $\mathrm{a}, \mathrm{b}$ and roof respectively, $A, B, H$ are referred as shape parameter vector, $\mathrm{M}$ is referred as volume vector, and $K_{a}, K_{b}, K_{d}$ are heat transfer coefficient matrixes. Then Eq. (8) can be written as:

$$
C L_{V}(\tau)=2 B Q_{a} M+2 A Q_{b} M+H Q_{d} M+\frac{1}{V} \sum_{i}\left(q_{a v i}-q_{a i}\right) F_{a w i}+\frac{1}{V} \sum_{i}\left(q_{b w i}-q_{b i}\right) F_{b w i}
$$

With corresponding terms equivalents between Eq.(10) and Eq.(11), we can obtain:

$$
\frac{1}{b^{\prime}} q_{a}^{\prime}=B Q_{a} M \frac{1}{a^{\prime}} q_{b}^{\prime}=A Q_{b} M \frac{1}{h^{\prime}} q_{d}^{\prime}=H Q_{d} M
$$

With the shape parameters in Table 1, heat transmission of building outer envelope can be expressed as:

$$
q_{a}^{\prime}=\frac{B Q_{a} M}{B M} q_{b}^{\prime}=\frac{A Q_{b} M}{A M} q_{d}^{\prime}=\frac{H Q_{d} M}{H M}
$$

There is a linear relationship between instantaneous heat transfer and heat transfer coefficient of building envelop. The relationship can be written as $q=K F \Delta T$, where $\Delta T$ is the instantaneous difference in temperature between inside and outside of buildings. So heat transfer coefficient of building $B^{\prime}$ is:

$$
K_{a}^{\prime}=\frac{B K_{a} M}{B M}, \quad K_{b}^{\prime}=\frac{A K_{b} M}{A M}, K_{d}^{\prime}=\frac{H K_{d} M}{H M}
$$

c) Window Thermal Factors of Building $B^{\prime}$

With corresponding terms equivalents between Eq. (10) and Eq.(11), we can obtain the parameter relationships of windows in facade a:

$$
\left(q_{a w}^{\prime}-q_{a}^{\prime}\right) \frac{F_{a w}^{\prime}}{V^{\prime}}=\frac{1}{V} \sum_{i}\left(q_{a w i}-q_{a i}\right) F_{a w i}
$$

Put the $F_{a w}^{\prime}$ expressed in Table 1 into Eq. (15), we can obtain:

$$
q_{a w}^{\prime}-q_{a}^{\prime}=\frac{\sum_{i}\left(q_{a w i}-q_{a i}\right) F_{a w i}}{\sum_{i} F_{a w i}}
$$


The denominator $\sum_{i} F_{a w i}$ in Eq.(16) represents the sum of window area in facade $a$ for all buildings of district, Let denote $m_{a w i}$ is the weight of window area of a building to total area, Eq.(16) can be presented as:

$$
q_{a w}^{\prime}-q_{a}^{\prime}=\sum_{i} q_{a w i} m_{a w i}-\sum_{i} q_{a i} m_{a w i}
$$

Shape and thermal parameters of walls have been confirmed. In the condition that there is little difference between $m_{a i}$ and $m_{a w i}$,we can consider as $q_{a}^{\prime} \approx \sum_{i} q_{a i} m_{a w i}$. In most cases, buildings in the same district have similar window to wall ratio, and also trends of $m_{a i}$ and $m_{a w i}$ are accordant. So $q_{a}^{\prime}$ and $\sum_{i} q_{a i} m_{a w i}$ in Eq.(17) can be eliminated and window instantaneous heat transfer of building $B^{\prime}$ can be expressed as:

$$
q_{a w}^{\prime}=\sum_{i} q_{a w i} m_{a w i} \approx \sum_{i} q_{a w i} m_{i}
$$

Similar with heat transfer of the wall, heat transfer coefficient and shading coefficient of the window can be dealt with the same method by reference to Eq. (14). Let denote $K_{a w}$ represents heat transfer coefficient of facade window $a$ and $S C_{a}$ represents shading coefficient, then:

$$
K_{a w}^{\prime}=\sum_{i} K_{a w i} m_{i} \quad S C_{a}^{\prime}=\sum_{i} S C_{a i} m_{i}
$$

In the same way, heat transfer and shading coefficient of facade window $b$ can be obtained:

$$
K_{b w}^{\prime}=\sum_{i} K_{b w i} m_{i} \quad S C_{b}^{\prime}=\sum_{i} S C_{b i} m_{i}
$$

\section{3) Virtual Building Model with Internal Factors}

Internal factors of buildings usually include person density, lighting power density, equipment power density, and so on. Mechanisms of these factors that product building cooling loads are homogeneous. There is a linear relationship between instantaneous heat produced by internal factors and instantaneous cooling loads. Because of changing in real time of the internal factors, we should determine factors of building $\mathrm{B}^{\prime}$ respectively by weighted superposition of each instantaneous distribution curve. The model with external factors used volume weighting and the internal model should keep identical with it. Usually, per unit area internal indexes are used to calculate building cooling loads, such as person number per unit area, lighting thermal per unit area, equipments thermal per unit area, and so on. So it is necessary to translate per unit area indexes into per unit volume indexes. It is easy to realize the translation with the height and layer numbers of buildings.

Let denote $P$ represents an instantaneous internal factor, $P(\tau)$ is the total instantaneous value of the district, and $P(\tau)=p V$. Let denote $P \quad p$ is the index value per unit volume of the district, $P_{i}$ is that of a single building. Then we can obtain as following:

$$
p=\frac{1}{V} \sum_{i} p_{i} V_{i}=\sum_{i} p_{i} m_{i}
$$

With Eq.(21), instantaneous internal factors of building $B^{\prime}$ can be calculated by $p^{\prime}=p$, where $p^{\prime}$ is the internal index value per unit volume of building $B^{\prime}$.

4) Virtual Building Model

From the analysis above we can obtain shape, envelope thermal and internal factor parameters of virtual building, as shown in Table 2

In Table 2, $\mathrm{E}$ is the correction matrix for building envelope heat transfer coefficient, and $\mathrm{E}$ is determined by the temperature of buildings. The coefficient is correction coefficient for heat transfer coefficient of external windows.

By Table 2, the parameter values about the shape and thermal factors of the virtual building can be determined by buildings in district with specific regulations. In fact, the regulations are weighted average methods. Each parameter of the virtual building can be determined by the weighted superposition of corresponding parameters of buildings in the district.

\section{VERIFICATION OF THE METHODOLOGY BY A CASE STUDY}

\section{A. Description of the Simulation Cases}

A case study of a district with 5 rectangle buildings in Beijing was conducted to verify the model. The district is a commercial district and building functions include office and business, as shown in figure 5. The shape and thermal parameters of district buildings and virtual building are listed in Table 3. Building $B^{\prime}$ is the virtual building of the district.

Assume that air conditioning design temperatures and relative humidity of all buildings are $25^{\circ} \mathrm{C}$ and $60 \%$, respectively, with homogeneous distribution in buildings. There are no external blinds in all buildings and air conditioning area of each building is equal to its construction area.

Simulation models of building $B_{1}, B_{2}, B_{3}, B_{4}, B_{5}$ and $B^{\prime}$ were set up with building energy simulation software VisualDOE4.0 to calculate hourly cooling loads. With superposition of hourly cooling loads of building $B_{1}, B_{2}, B_{3}$, $B_{4}, B_{5}$, we can get load distribution of the district and also the hourly loads per unit volume. Meanwhile, hourly loads per unit volume of building $B^{\prime}$ can be calculated. By comparison of the district and building $B^{\prime}$, virtual building model in Table 2 can be verified. 
TABLE II. VIRTUAL BUILDING MODEL PARAMETERS

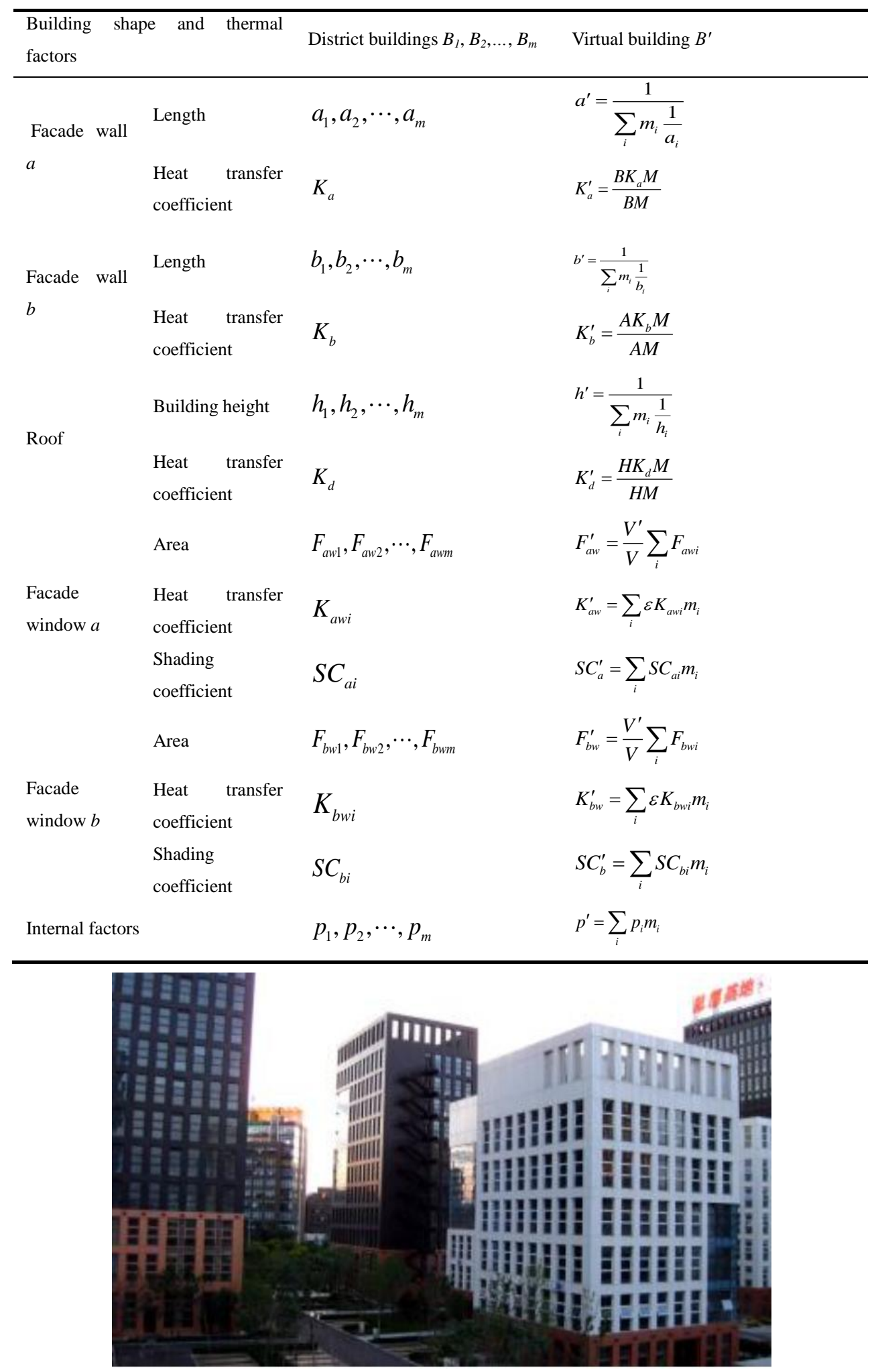

Figure 5. A commercial district in Beijing. 
TABLE III. SHAPE AND THERMAL PARAMETERS OF DistRICT BUILDINGS AND VIRTUAL BUILDING.

\begin{tabular}{|c|c|c|c|c|c|c|}
\hline Building category & $B_{1}$ & $B_{2}$ & $B_{3}$ & $B_{4}$ & $B_{5}$ & $B^{\prime}$ \\
\hline Length of facade wall $a(\mathrm{~m})$ & 80 & 75 & 20 & 40 & 40 & 44.5 \\
\hline Length of facade wall $b(\mathrm{~m})$ & 20 & 25 & 60 & 20 & 60 & 31.3 \\
\hline Height of building $(\mathrm{m})$ & 40 & 40 & 28 & 40 & 50 & 41 \\
\hline $\begin{array}{l}\text { Heat transfer coefficient of facade } \\
\text { wall } a\left(\mathrm{~W} / \mathrm{m}^{2} \cdot \mathrm{k}\right)\end{array}$ & 1.0 & 0.8 & 0.5 & 0.6 & 0.4 & 0.74 \\
\hline $\begin{array}{l}\text { Heat transfer coefficient of facade } \\
\text { wall } b\left(\mathrm{~W} /\left(\mathrm{m}^{2} \cdot \mathrm{k}\right)\right)\end{array}$ & 1.0 & 0.8 & 0.5 & 0.6 & 0.4 & 0.56 \\
\hline Volume ratio $\left(m_{i}\right)$ & 0.197 & 0.231 & 0.104 & 0.099 & 0.369 & $V^{\prime} / V=0.176$ \\
\hline Window areas of facade wall $a\left(\mathrm{~m}^{2}\right)$ & 1600 & 1472 & 134.4 & 512 & 640 & 767 \\
\hline Shading coefficient of facade wall $a$ & 0.5 & 0.4 & 0.3 & 0.35 & 0.45 & 0.42 \\
\hline Window areas of facade wall $b\left(\mathrm{~m}^{2}\right)$ & 192 & 320 & 851.2 & 192 & 1152 & 476.5 \\
\hline Shading coefficient of facade wall $b$ & 0.5 & 0.4 & 0.3 & 0.35 & 0.45 & 0.42 \\
\hline $\begin{array}{l}\text { Heat transfer coefficient of windows } \\
\left(\mathrm{W} / \mathrm{m}^{2} \cdot \mathrm{k}\right)\end{array}$ & 2.8 & 2.3 & 2.0 & 3.5 & 3.0 & 2.7 \\
\hline $\begin{array}{l}\text { Heat transfer coefficient of roofs } \\
\left(\mathrm{W} / \mathrm{m}^{2} \cdot \mathrm{k}\right)\end{array}$ & 0.3 & 0.35 & 0.28 & 0.35 & 0.3 & 0.31 \\
\hline Person density $\left(\mathrm{m}^{2} / \mathrm{p}\right)$ & 10 & 20 & 5 & 30 & 15 & 15.6 \\
\hline Lighting power density $\left(\mathrm{W} / \mathrm{m}^{2}\right)$ & 11 & 9 & 20 & 15 & 10 & 11.5 \\
\hline Equipment power density $\left(\mathrm{W} / \mathrm{m}^{2}\right)$ & 20 & 15 & 30 & 10 & 20 & 18.9 \\
\hline Fresh air volume $\left(\mathrm{m}^{3} / \mathrm{h} . \mathrm{p}\right)$ & 20 & 30 & 20 & 20 & 20 & 22.3 \\
\hline
\end{tabular}

In simulation models, Typical Meteorological Year (TMY) data of Beijing are used. Internal factor in Table 3 used design values, so it is necessary to choose their day's schedules. By characteristics of buildings in the district, three type schedules are showed in figure 6. Internal factor schedules of building $B_{1}, B_{2}, B_{3}, B_{4}, B_{5}$ are chosen from figure 6, as showed in Table 4 .

TABLE IV. INTERNAL FACTOR SCHEDULES OF DISTRICT BUILDINGS.

\begin{tabular}{lccccc}
\hline Building category & $B_{1}$ & $B_{2}$ & $B_{3}$ & $B_{4}$ & $B_{5}$ \\
\hline Person density & (a) & (c) & (d) & (c) & (c) \\
$\begin{array}{l}\text { Lighting power } \\
\text { density }\end{array}$ & (a) & (a) & (b) & (b) & (b) \\
$\begin{array}{l}\text { Equipment power } \\
\text { density }\end{array}$ & (a) & (a) & (b) & (b) & (b) \\
Fresh air volume & (a) & (b) & (b) & (c) & (c)
\end{tabular}

As showed in Table 4, because of similar control modes, person density has the same schedule with fresh air volume, and lighting power density has the same schedule with equipment power density.

Two types of district schedules are obtained after hourly superposition of internal factor schedules of five buildings, showed as figure 7 and figure 8 . Let denote building $B^{\prime}$ has the same internal factor schedules with the district.

\section{B. Results}

1) Comparisons of the District and the Virtual Building

Then annual hourly cooling loads of building $B_{1}, B_{2}, B_{3}$, $B_{4}, B_{5}$ and $B^{\prime}$ can be calculated with shape, thermal and internal factor parameters above. Values of 120 hours between July 30th and August 4th were chosen from simulation results of annual hourly cooling loads, because the maximum temperature of summer in Beijing usually occurs in the period.

Figure 9 is hourly cooling loads curves of building $B_{1}, B_{2}$, $B_{3}, B_{4}, B_{5}$. The district load curve can be obtained with hourly superposition of five buildings. The load curve of building $B^{\prime}$ can be directly obtained by simulation model.

Hourly cooling loads per unit volume curves of the district and building $B^{\prime}$ are showed in figure 10, which are the division of hourly cooling loads by their volumes. The abscissa of figure 9 or figure 10 is the time with 120 hours. The ordinate of figure 9 is the value of hourly cooling load and figure 10 the load per unit volume. Figure 10 shows that the hourly cooling loads per unit volume curve of the district keeps in good agreement with the curve of building $B^{\prime}$. 


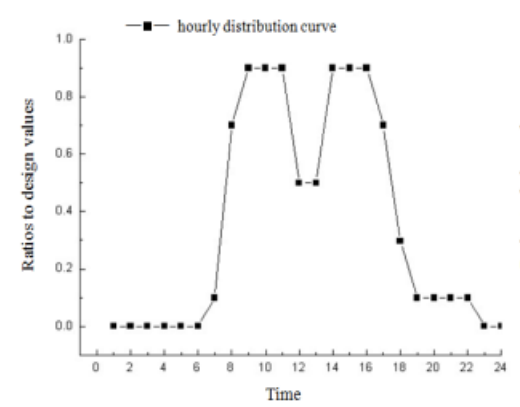

(a)

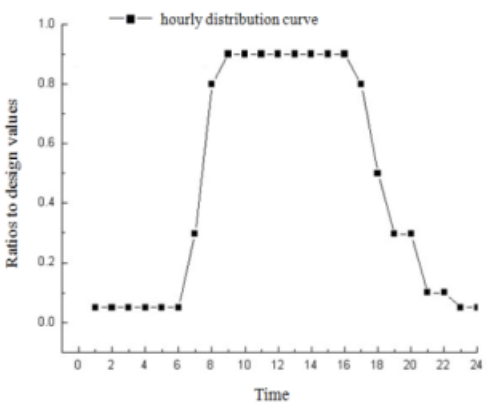

(b)

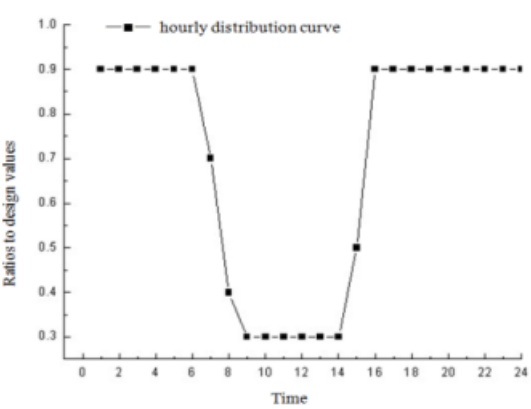

(c)

Figure 6. Schedules of Buildings in the District.

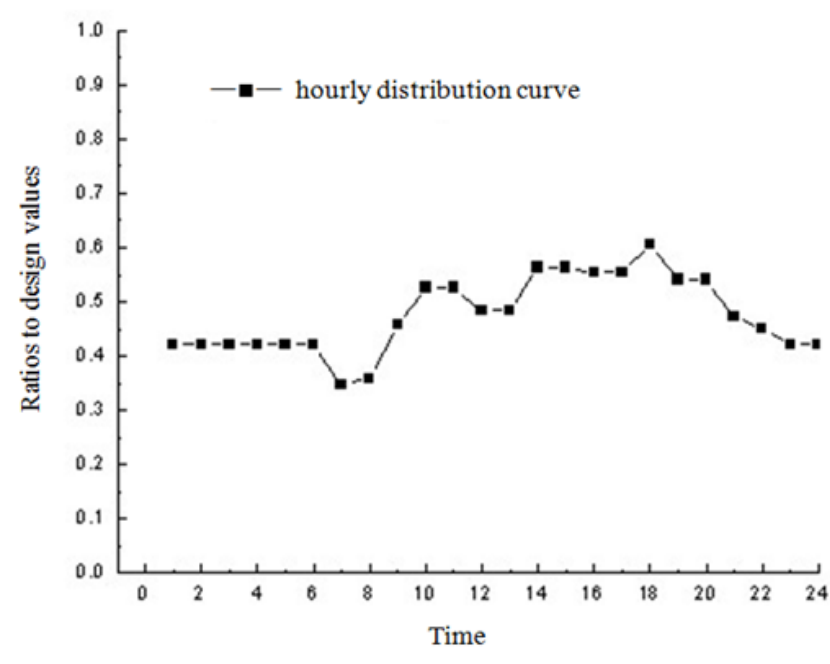

Figure 7. Schedule of Person Density or Fresh Air Volume for Building

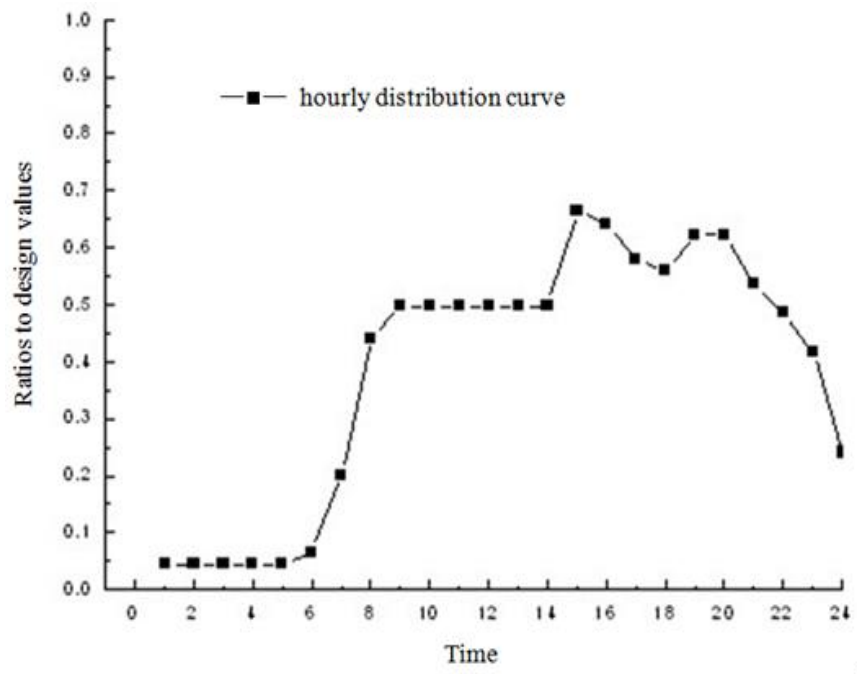

Figure 8. Schedule of Lighting or Equipment Power Density for Building

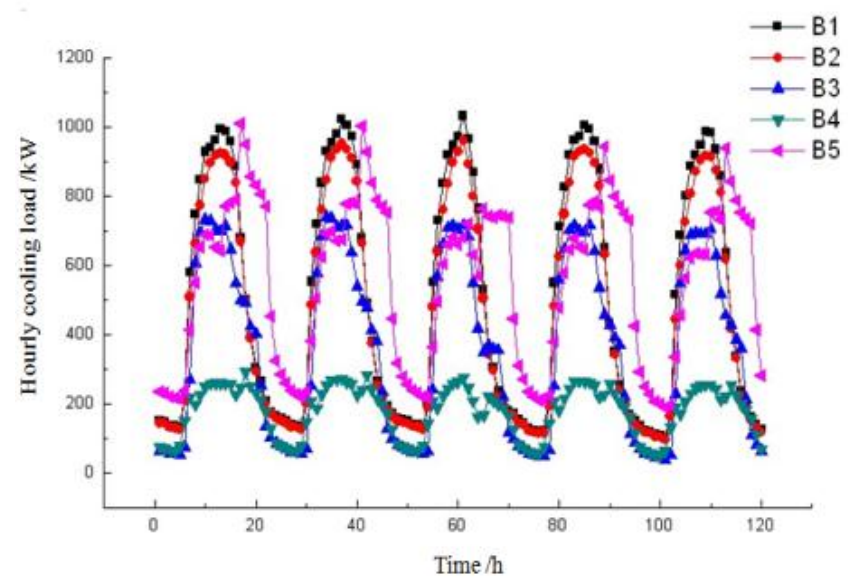

Figure 9. Hourly Cooling Load Curves of Building $B_{1}, B_{2}, B_{3}, B_{4}, B_{5}$.

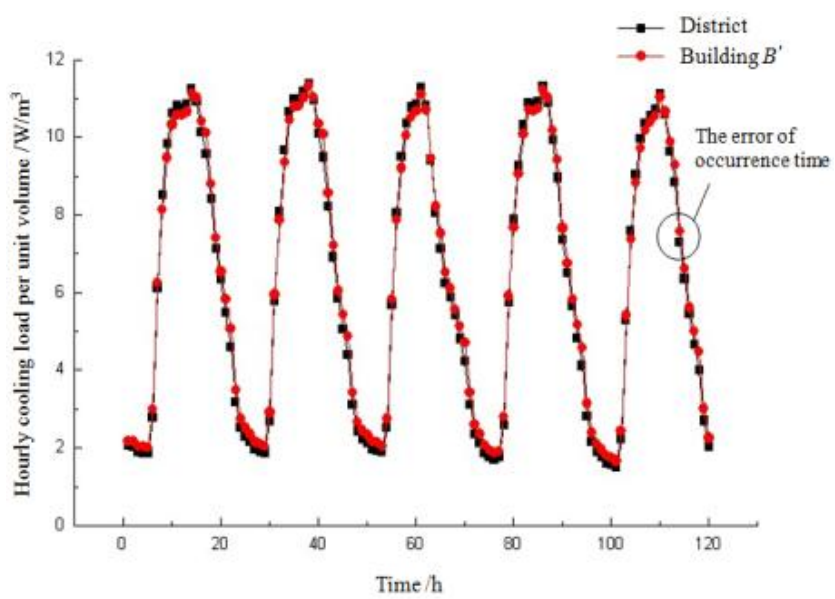

Figure 10. Hourly Cooling Loads Per Unit Volume Curves of the District and Building $\mathrm{B}^{\prime}$.

\section{2) Error Analysis}

With comparisons of results between the district and building $B^{\prime}$, the maximum absolute value of relative error is $10.3 \%$. The average absolute value of relative error is about $5 \%$. The peak of hourly cooling loads occurs in the period of 
10:00 am to $15: 00 \mathrm{pm}$ each day and the maximum absolute value of relative error in this period is only $2.7 \%$. The errors completely meet the project requirements.

Most of the errors are caused by errors of occurrence time, which means that some instantaneous values of building $B^{\prime}$ curve migrate in time dimension. The source of errors of occurrence time is the change of internal space structure in integrated virtual building from district buildings. The change leads to the time differences when building heat gains caused by internal factors transform into cooling loads. It is sometimes impossible to keep clear of this kind of error in the model.

\section{APPLICATION OF THE METHODOLOGY}

The model can provide a way to calculate instantaneous cooling loads of district buildings. And also, the model can predict district cooling loads in energy planning. The district energy planning is usually performed in the stage of regulatory planning, in which subdivision of land has been determined and regulatory index system is built, but buildings have not been designed. In these conditions, virtual building of the district can be established with regulatory indexes including land use, the number of people, building volume, plot ratio, energy conservation design standard, and so on.

\section{CONCLUSIONS}

The paper discusses relationships of hourly cooling loads between single buildings and the district. A virtual building model is established whose distribution of hourly cooling loads per unit volume is the same as that of superposition of all single buildings in the district. Parameter values of simulation model for the virtual building can been determined by buildings in the district with weighted average methods. Each parameter of the virtual building can be determined by the weighted superposition of corresponding parameters of buildings in the district. The case study shows that hourly cooling loads per unit volume curve of virtual building model keeps in good agreement with the curve of the district. So cooling loads of single buildings established contact with the district by the virtual building.

In the stage of urban regulatory planning, which detailed information of single buildings is limited, virtual building determined by regulatory indexes plays a bridge role between single buildings and the district.

\section{ACKNOWLEDGMENT}

This work is supported by the financial support of the starting research funds of North China University of Technology.

\section{REFERENCES}

[1] W.D. Long, Wei Bai, et al. (2008) Community building energy planning: the base of energy efficiency, Construction Science and Technology(in Chinese), z1, 61-65

[2] Howard B, Parshall L, Thompson J, et al. (2012) Spatial distribution of urban building energy consumption by end use, Energy and Buildings, 45: 141-151

[3] L. Pedersen, J. Stang, R. Ulseth. (2008) Load prediction method for heat and electricity demand in buildings for the purpose of planning for mixed energy distribution system, Energy and Buildings 40:1124-1134

[4] Theodoridou I, Papadopoulos A M, Hegger M. (2011) Statistical analysis of the Greek residential building stock, Energy and Buildings, 43: $2422-2428$

[5] Z.J. Hou, Z.W. Lian, Y. Yao, X.J. Yuan. (2006) Cooling-load prediction by the combination of rough set theory and an artificial neural-network based on data-fusion technique, Applied Energy 83 1033-1046

[6] H.F. Zheng, J. Bai, A.G. Li. (2007) Application review of BP neutral network for prediction of cooling load in air conditioning for building, Computer Applications and Software, 24: 103-105

[7] Corgnati S P, Corrado V, Filippi M. (2008) A method for heating consumption assessment in existing buildings: a field survey concerning 120 Italian schools, Energy and Buildings, 40: 801-809

[8] Bouyer J, Inard C, Musy M. (2011)Microclimatic coupling as a solution to improve building energy simulation in an urban context, Energy and Buildings, 43: 1549-1559

[9] Lin Duanmua, Zhenjiang Wang. (2013)Simplified method to predict hourly building cooling load for urban energy planning, Energy and Buildings , 58:281-291

[10] T.T. Chow, K.F. Fong, A.L.S. Chan, et al. (2004) Energy modeling of district cooling system for new urban development, Energy and Buildings, 36:1153-1162

[11] Tarabieh K A, Malkawi A M. (2007) Building an urban energy performance framework: integrating spatial analysis and building simulation tools for campus planning, Energy and Buildings, (1/2/3) 1839-1845

[12] Xiang Yuan, W.D. Long. (2009) Parametric analysis of building orientation in forecasting community building cooling loads and it's transformation regulation, Journal of Civil Architectural \& Environmental Engineering(in Chinese), 31, No.6:97-10 